\title{
Leprosy Scenario in Nepal
}

\author{
Jain $M C^{1}$ \\ 'Nepalguni Medical College, Nepal
}

\section{INTRODUCTION}

Nepal is a known leprosy endemic country of having a population of 26.1 millions, ${ }^{1}$ and is one of the four countries in the world that have not achieved elimination yet. Leprosy has been recognized as a public health problem since time immemorial and efforts were made to combat it in all earnestness.

With an estimated number of 100,000 Leprosy cases, in the year 1966, leprosy control program using Dapsone mono therapy was started as a pilot project in Nepal. ${ }^{2}$ This project gradually expanded as a vertical program and remained so till 1987 when it was integrated into general health services. ${ }^{2}$ Multi drug therapy (MDT) was introduced for the first time in Nepal in the year $1982 / 83$ in selected few areas and hospitals. By that time number of registered cases had come down to 31537 (PR of 21 per 10,000). 2,3 Number of districts then with a prevalence rate (PR) of over 5 was 62 and in only three districts the PR was less than 1 per $10,000 .^{2}$ There was a gradual and steady expansion of MDT services and by the year 1996 MDT coverage was extended to all the 75 districts of the country. ${ }^{2-4}$

Being a member country, Nepal is committed to the cause of elimination of leprosy in line with the global program and is an active member of the global alliance for elimination of leprosy as a public health problem. ${ }^{5} \mathrm{~A}$ six-year plan was developed in 1995 for strengthening the program. ${ }^{2,3}$ Accordingly, as per that plan, an estimation of leprosy prevalence was done and all basic health staff (BHS) were provided training in Leprosy. Health Education was intensified to improve community awareness and to facilitate case detection.

The first independent evaluation of the National Leprosy Control Program (NLMP) was undertaken during January (7th to 26th) 1996, by a group of experts representing His Majesty Government (HMG), World Health Organization (WHO) and National Government Organizations (NGOs). ${ }^{2,3}$ The team had appreciated the performance of NLEP. Two rounds of Leprosy Elimination Campaigns were organized in the years 1999 and 2000.4 To assess the performance and the progress towards elimination Leprosy Elimination Monitoring exercises were conducted Case validation was done through independent evaluators. ${ }^{2,3}$

\section{LEPROSY SERVICE DELIVERY}

All the peripheral Health Facilities (HFs) numbering around 4190 (Health Posts, Sub Health Posts and Primary Health Centers) are providing services to leprosy patients. ${ }^{2-4}$ Most of the basic health staff numbering about 19,445 has undergone Comprehensive Leprosy Training (CLT)

\author{
Correspondence \\ Dr. M. C. Jain \\ Department of Dermatology \\ Nepalguni Medical College, Nepal. \\ Email: baidmcjn@yahoo.com
}


Jain. Leprosy Scenario in Nepal

and a majority of them an additional Refresher Leprosy Training (RLT) as well. ${ }^{3,4}$ These health facilities (HFs) carry out leprosy diagnosis and treatment services, patient counseling, contact examination, community health education, focal case detection drives, treatment of minor complications and referral services. In addition over $90 \%$ of Female Community Health Volunteers have been provided with orientation training. ${ }^{4}$ There is a good network of Referral Centers managed b international government organizations (INGO's)/NGOs that are providing secondary and tertiary general health care in the country. ${ }^{2}$

\section{Managerial support}

District Leprosy and Tuberculosis assistant posted at each district is the first line manager and is providing managerial and technical support to the staff working at $\mathrm{HFs} .{ }^{4}$ At the regional level there is regional tuberculosis leprosy assistant (RTLA) to assist the program. ${ }^{2}$ There is a Leprosy Control Division located at the center headed by Director, mainly responsible for laying down the policy, deciding on the strategy of leprosy control and issuing periodically updated national guidelines for leprosy control activities in the country. ${ }^{4}$

There are several partners (INGOs and NGOs) who provide human, material and financial support to NLEP. The major partners are The Leprosy Mission International, Sasakawa Memorial Health Foundation, Netherlands Leprosy Relief Association, International Nepal Foundation, Nepal Leprosy Fellowship and Nepal Leprosy Trust. ${ }^{2-4}$

\section{NLEP Objectives:}

Following are the explicitly stated objectives of NLEP. ${ }^{4}$

- To reduce PR to $<1 / 10,000$ and continue to reduce it further.

- To prevent disabilities due to leprosy.

- To reduced stigma against the disease in the community.

\section{NLEP Strategies ${ }^{4,5}$}

In the absence of an effective health promotion and specific protective measures against leprosy in man the programme has to depend on Secondary Prevention namely "Early Diagnosis and Prompt Treatment". This strategy had remained unchanged and unchallenged for over half a century.

\section{CURRENT LEPROSY SITUATION}

Current leprosy disease burden and its trend

Number of leprosy cases have decreased dramatically from an estimated 100000 in 1961 to a mere 3786 as on $15^{\text {th }}$ July 2007 . The fiscal year $2006 / 07$ has shown an over all $11.7 \%$ decrease in registered cases. ${ }^{4}$

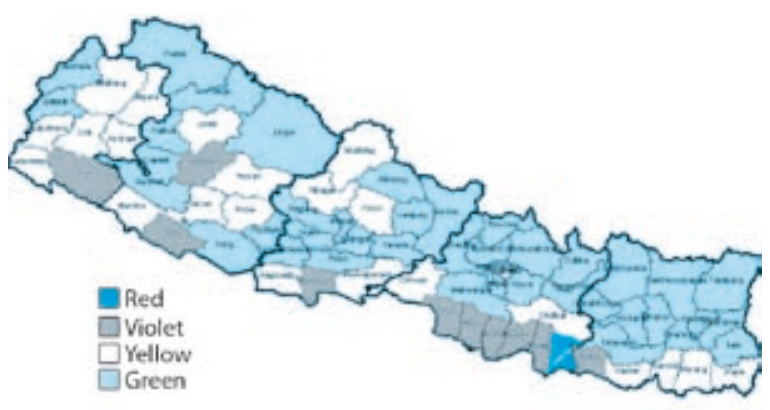

Fig 1. District wise endemic of leprosy

The above map shows the district according to endemicity. There is just one district in Nepal with a registered PR of $3.1 / 10000$ (Red). ${ }^{4}$ In ten districts the PR is between 2 to 3 (Violet) while in 22 districts the PR is between one and two (yellow). There are 42 districts where the PR is below 1 (green). ${ }^{4}$

In figure 2 below the proportion of cases detected during the year 2006/07 and the proportion of the registered cases on the registers at the year end in 5 regions is given. ${ }^{4}$

As was the case earlier two regions namely central development region (CDR) and eastern development region (EDR) accounts for around two thirds of the case load in Nepal. Figure 4 below show the number of cases detected and registered in five regions of Nepal. ${ }^{4}$

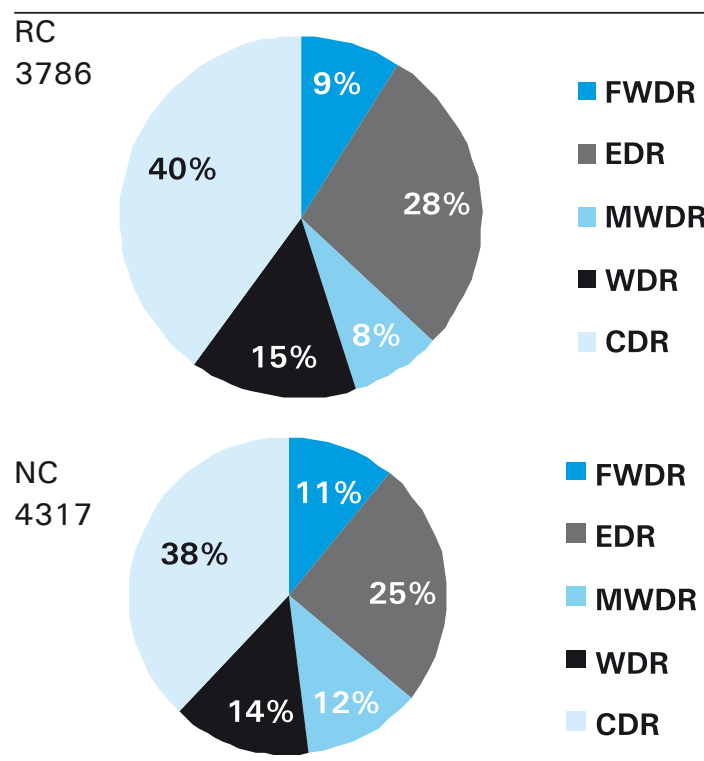

Fig 2. Distribution of cases according 5 regions 
Jain. Leprosy Scenario in Nepal
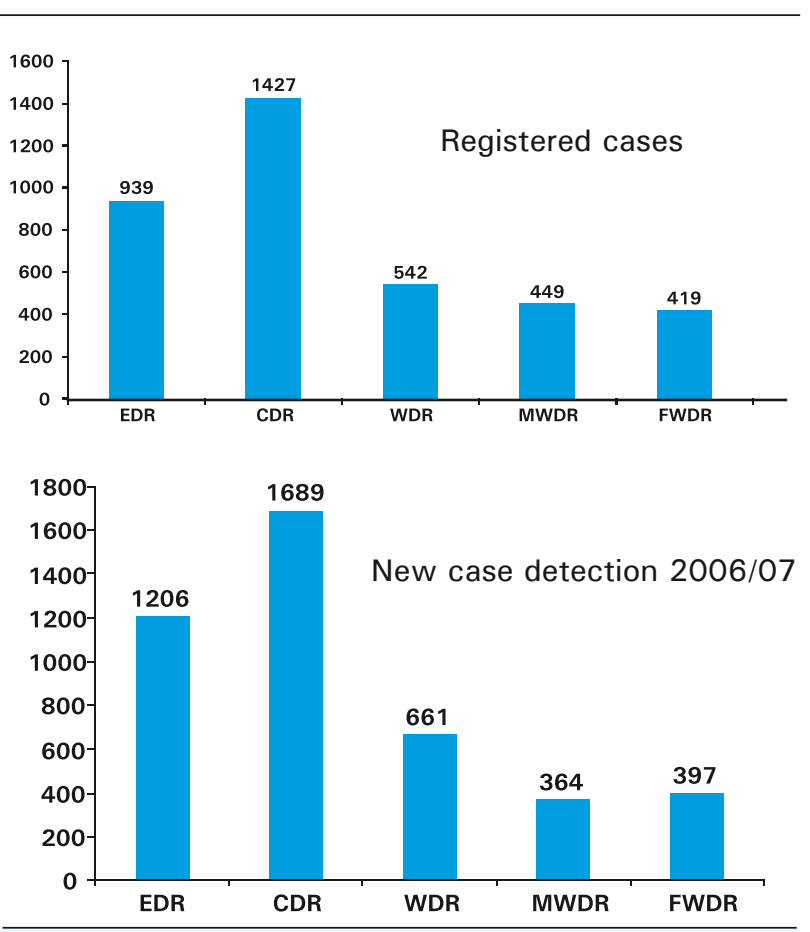

Fig 3. Cases detected and registered in 5 regions

$E D R=$ Eastern Development region, $C D R=$ Central Development Region, WDR $=$ Western Development Region, $M W D R=$ Mid-west Development Region, FWDR $=$ Far-western Development Region, NCDR $=$ New Case Detection Rate
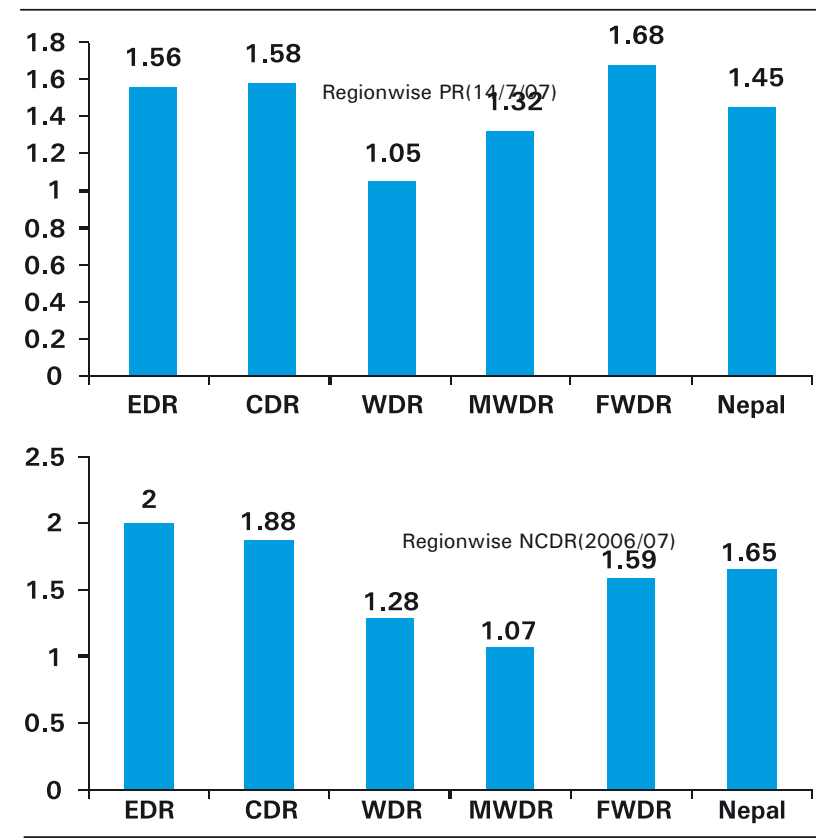

Fig 4. Region wise PR and NCDR

Figures above reveal that maximum numbers of cases are form CDR followed by EDR where as the PR is highest in FWDR (1.68) and least in western development region (WDR) and highest new case detection rate (NCDR) is reported from $\operatorname{EDR}(2 / 10,000) .{ }^{4}$
During the year 2006/07 a total of 4317 new leprosy cases were detected. Among these new cases detected during the second quarter there were women patients were $23.1 \%$ and Children were $6 \%$. Proportion of MB cases was $55 \%$. Proportion of leprosy cases having disability GR II at the time of detection was giving a Disability rate of $5.56 \% .^{4}$

Treatment compliance continue to be good in Nepal however this year saw an increase in PD ratio from $0.84(2005 / 06)$ to $0.88(2006 / 07) .{ }^{4}$ The ratio remained less than one in all regions barring two namely FWDR In the figure 6 and 7 below trends over the past five years of important indicators is given. ${ }^{4}$

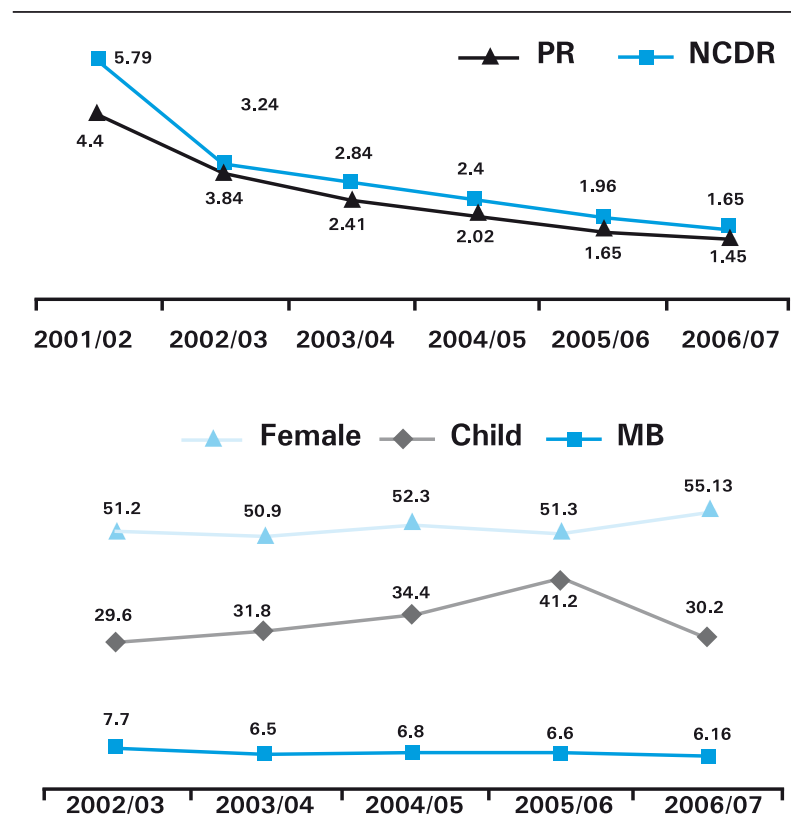

Fig 5. Trends in selected indicators over the past 5 years

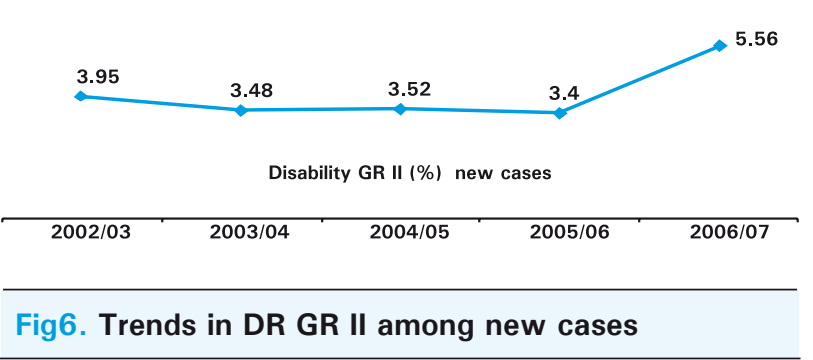

Figures 6 and 7 show that the indicators are by and large stable excepting that during the last year DR has gone up and Female proportion among new cases has come down.

With the continuation of current declining trend and same level of leprosy control activities PR by the year end of 2007 was expected to cross over to less than one. $^{4}$ 
Jain . Leprosy Scenario in Nepal

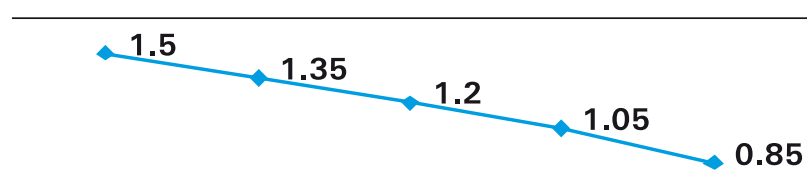

Projected PR in Nepal

2006 Nov' 2007 Mar 2007 Jul 2007 Nov 2008 Mar

Fig 7. Projected trend in PR in Nepal

The projections did not come true. Declining trend continued but at a reduced rate during the last year. Some of the planned activities could not be carried out in endemic districts due to disturbances.

\section{CHALLENGES}

In spite of the consistently declining PR the country has not reached elimination level. Additional efforts are needed to expedite the process of elimination. Uneven distribution of registered cases numbering a mere 3786 had resulted in the districts with no cases, districts with sporadic cases, low endemic districts and endemic districts. This calls for a realistic and practical area specific approach.

There are few districts and areas within the districts that throw up large number of new cases year after year. The control activities are either grossly inadequate or these areas are relatively inaccessible. May be there are some yet unknown factors operating that has favored a high intensity of leprosy transmission. These areas can not be left alone. They have to be mapped and mopped up so as to prevent them from becoming the source for future resurgence of leprosy.

Present policy of providing MDT services at all peripheral health facilities particularly in very low endemic districts is not practical and becoming increasingly cost in effective. Alternate approaches that are cost effective have to be identified and implemented.

Tasks involved in client management go unsupervised by first line managers. Most of the time supervision is limited to perusing records and reports. As a result NLEP is forced to organize special activities to monitor diagnostic efficiency of staff. Case review should become a routine task of supervisors.

Most of the trained manpower remains under and or unutilized either due to inadequate motivation or due to lack of demand. Hence there is an urgent need to undertake an in depth evaluation of leprosy training.

Leprosy Control Division in particular and the programme in general is heavily dependent on external support from either INGOs or WHO.

On going persistent agitation in the plains has affected movement in few districts of CDR and EDR. The districts that are affected most by agitation incidentally are the districts of very high case load. For the time being implementation of activities aimed at expediting elimination in these districts is quite uncertain.

\section{Proposed additional activities}

Detection and deletion of cases inappropriately registered has to be undertaken in endemic district so as to expedite elimination. In addition updating of records and ensuring correct data compilation will also help in minimizing errors in data aggregation. ${ }^{4}$

Phases and planned centralization of service delivery at selected few points will facilitate sustaining quality service delivery at an affordable cost.

Involving medical colleges in capacity building and provision of secondary care to leprosy patients will ensure sustainability.

\section{CONCLUSION}

Nepal is one of the four countries in the world that has not yet achieved elimination of leprosy as a public health problem though the country has been reporting a steady decline both in PR and NCDR but the decline is not fast enough to reach elimination by the end of 2007. It has been observed that Operational factors such as re-registration, registration of Indian cases and wrong diagnosis have a significant role in inflating PR in Nepal. Case holding in Nepal is exceptionally good with the cure rates of over $91 \%$ for $\mathrm{MB}$ and $94 \%$ for PB cases. Endemicity of leprosy is mainly localized to Terai region accounting for $80 \%$ cases under treatment and $82 \%$ new cases detected. An effective cross referral system is in place. Program is assisted by a good network of supporting partners. Concerted efforts are being made to minimize the operational factors and improve the quality of leprosy services in order to attain the goal of leprosy elimination as soon as possible. 


\section{REFERENCES}

1. Ministry of Population and Environment and Central Bureau of Statistics. Population Projections for Nepal 2001-2007. Kathmandu: Ministry of Population and Environment and Central Bureau of Statistics Nepal; 2003.

2. Leprosy Control Division, Department of Health Services, His Majesty's Government of Nepal Ministry of Health and Population. Annual report 2062/2063 (2005/2006). Kathmandu: Leprosy Control Division; 2006 Nov 7. 29p.

3. Leprosy Control Division, Department of Health Services, His Majesty's Government of Nepal Ministry of Health and Population. Annual report 2061/2062 (2004/2005). Kathmandu: Leprosy Control Division; 2005 Oct 9. 20p.

4. Leprosy Control Division, Department of Health Services, His Majesty's Government of Nepal Ministry of Health and Population. Annual report 2063/2064 (2006/2007) $1^{\text {st }}$ Draft. Kathmandu: Leprosy Control Division; 2007. 30p.

5. World Health Organization. Global Strategy for Further Reducing the Leprosy Burden and Sustaining Leprosy Control Activities (2006-2010) Operational Guidelines. New Delhi: WHO; 2006. 50p. Report no.SEA/GLP/2006.2. 